\title{
Correction to: Scientific white paper on concentration-QTc modeling
}

\author{
Christine Garnett ${ }^{1}$ (D) Peter L. Bonate ${ }^{2}$ Q Qianyu Dang ${ }^{4} \cdot$ Georg Ferber $^{3} \cdot$ Dalong Huang $^{4} \cdot$ Jiang Liu $^{5}$.

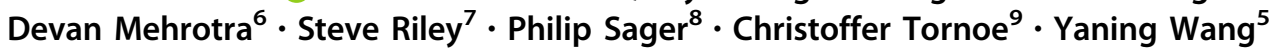

Published online: 12 January 2018

(C) Springer Science+Business Media, LLC, part of Springer Nature 2018

\section{Correction to: \\ Journal of Pharmacokinetics and Pharmacodynamics https://doi.org/10.1007/s10928-017-9558-5}

The original version of this article unfortunately contained an error in Equation 1 under the section "Pre-specified linear mixed effects model". The correct equation has given below:

$$
\begin{aligned}
\Delta Q T c_{i j k}= & \left(\theta_{0}+\eta_{0, i}\right)+\theta_{1} T R T_{j}+\left(\theta_{2}+\eta_{2, i}\right) C_{i j k} \\
& +\theta_{3} T I M E_{j}+\theta_{4}\left(Q T c_{i, j=0}-\overline{Q T c_{0}}\right)
\end{aligned}
$$

The original article has been corrected.

The original article can be found online at https:// doi.org/10.1007/s10928-017-9558-5.

Christine Garnett

christine.garnett@fda.hhs.gov

1 Division of Cardiovascular and Renal Products, Office of New Drugs, Center for Drug Evaluation and Research, Food and Drug Administration, Silver Spring, MD, USA

2 Astellas Pharma Global Development, Northbrook, IL, USA

3 Statistik Georg Ferber GmbH, Riehen, Switzerland

4 Office of Biostatistics, Office of Translational Sciences, Center for Drug Evaluation and Research, Food and Drug Administration, Silver Spring, MD, USA

5 Division of Pharmacometrics, Office of Clinical Pharmacology, Office of Translational Sciences, Center for Drug Evaluation and Research, Food and Drug Administration, Silver Spring, MD, USA

6 Biostatistics, Merck \& Co., Inc., Gwynedd, PA, USA

7 Clinical Pharmacology, Pfizer Inc., New York, NY, USA

8 Stanford University, Stanford, CA, USA

9 Clinical Reporting, Novo Nordisk A/S, Bagsværd, Denmark 